\title{
THE DEVELOPMENT OF A USABILITY INSTRUMENT FOR E-LEARNING IN EDUCATIONAL SETTINGS
}

\author{
Zoroayka V. Sandoval, The University of Texas Rio Grande Valley, vicky.sandoval@gmail.com
}

\begin{abstract}
Determining the usability of fully online courses will help faculty and designers improve the design of online courses and it is expected, students' overall experience. Few studies assess usability focused on e-learning. While research has been conducted on usability, it usually do not address pedagogical elements that are necessary for designing highly effective fully online courses. The E-learning Usability Evaluation Questionnaire created by Zaharias [29] is the closest instrument found to measure usability, including pedagogical elements and students' motivation to learn. However, it was created for corporate settings. The purpose of this article is to present a brief review of literature, the research problem, methodology, and limitations of a proposed study designed to revise and test the adapted version of the E-learning Usability Evaluation Questionnaire [29] to educational settings using a Delphi study.
\end{abstract}

Keywords: Usability, e-learning, Fully Online Course, Pedagogical Usability

\section{INTRODUCTION}

The use of fully online courses has increased in undergraduate and graduate levels of education [1]. Online courses are usually designed, developed, and/or taught by people with different design-skills, producing courses with different design levels. This results in a wide range of experiences for users. According to the research [13, 18, 26], course design plays an important role in students' satisfaction, as well as preventing frustration and enhancing the learning experience.

In fully online courses, most of the students' interactions are through the Internet by using web interfaces. Recent research has started to focus on e-learning usability to create courses that are easy for students to use and reduce frustration an online course may produce. Usability, as defined by the International Standard ISO 9241-11, is "the extent to which a product can be used by specified users to achieve specified goals with effectiveness, efficiency, and satisfaction in a specified context of use"[18]. Nielsen [21] argues that if a user finds a website interface difficult to use, or gets lost in it, he or she will leave the website, and find another one that is easier-to-use. Online students have no choice. They have to use the designated web interface during the entire course, which, depending on the interface design, may produce either frustration or satisfaction.

A well-known method for improving website's usability is using the heuristics developed by Nielsen [19]. Several usability evaluations of e-learning settings have been conducted by researchers using the heuristic evaluation $[4,5$, 6 , 7]. However, since the purpose of e-learning is not only to provide an interface for an online learning environment, but also to support the acquisition of knowledge through it, the traditional usability instruments are not sufficient [25]. Zaharias and Koutsabasis [30] state, "usability of e-learning systems and applications is directed toward optimizing the learner experience along the two main axes: technical (or web) usability and pedagogical usability." Based on this, a usability measurement of a fully online course should consider not only the web interface design, but also pedagogical components such as communication and learning tools, content, and tasks included in the learning environment [27].

Several researchers have considered additional pedagogical components when conducting usability evaluations to elearning environments $[15,8,29,22]$ and new heuristic checklists are also proposed. Scarcer studies were found where the overall usability, including pedagogical components, are tested in courses with similar characteristics as the fully online courses offered at university level $[29,15]$. There are instruments that are proprietary, such as Quality Matters to assess the quality of online courses. However, they are very costly, both in cost and training time for users and require the fulfillment of many prerequisites. The E-learning Usability Evaluation Questionnaire created by Zaharias [29] is the closest free and available instrument found to measure usability. Since it was designed to be used in corporate settings, an adaptation is required in order to measure usability in educational 
settings.

This article will present a proposal for a study in which the E-learning Usability Evaluation Questionnaire created by Zaharias [29] will be adapted for e-learning environments. Faculty teaching online and online-course designers could benefit from having access to an e-learning usability instrument to aid in the design and evaluation of fully online university courses. The instrument could assist them in examining to what degree they have incorporated usability principles to the designed courses. The results of the usability evaluation will help stakeholders in the improvement of the design of the courses and as a consequence, the overall experience of the final users.

\section{THE RESEARCH PROBLEM}

A review of literature on usability and instruments designed to assess it revealed that there is no specific instrument available to help guide and evaluate usability in fully online university-level courses. In the recent studies found, usability in e-learning courses or trainings has been evaluated by using different instruments such as usability heuristics [4, 5, 7, 9], User Centered Design (UCD) guidelines [10, 12], and self-developed checklists [2, 3]. A common used instrument is the heuristic evaluation which evaluates the presence of the following ten heuristics developed by Jakob Nielsen [19]: (1) visibility of system status, (2) match between system and the real world, (3) user control and freedom, (4) consistency and standards, (5) error prevention, (6) recognition rather than recall, (7) flexibility and efficiency of use, (8) aesthetic and minimalist design, (9) help users recognize, diagnose, and recover from errors, and (10) help and documentation.

According to Nielsen [20], the heuristic evaluation "is a usability engineering method for finding the usability problems in a user interface design so that they can be attended to as part of an iterative design process." Some studies addressing usability evaluation of e-learning using Nielsen's heuristics [19] were found. For example, Davids, Chikte, and Halperin [7] identified several usability problems in a health-science online application using heuristic evaluation. Experts and final users completed the evaluations and found some issues that could improve the interface's usability. However, a drawback of using it in online educational settings is that the outcomes of this method provide insight on the improvement of web interface elements and interaction, without considering pedagogical elements.

Research $[11,8,23,30]$ has affirmed that a usability evaluation conducted in educational-purpose settings should assess also pedagogical aspects of e-learning. Online-course designers and developers should consider not only technical usability to ensure a good user-experience while navigating through the course, but also pedagogical usability in order to support students' learning throughout the course. A summary of several studies found where different criteria are used to evaluate usability on e-learning is presented in Table 1 below. These studies were categorized according to what they assessed, into the following 2 categories: (1) technical usability, or (2) technical and pedagogical usability.

A few usability-measuring studies were found where additional e-learning pedagogical elements were considered. Khan, Israr, and Hassan [17] conducted an evaluation of web office applications, which can be used by business organizations, entertainment industry, social interaction networks, and also for collaborative study in educational systems. In order to evaluate usability of this collaborative writing system, they used the Think Aloud Protocol considering in their questionnaire five different criteria: (1) effectiveness, (2) efficiency, (3) satisfaction, (4) learnability, and (5) utility [17]. In addition to interface evaluation, these criteria provide additional resources to evaluate usability, however, this study does not focused on online courses. The purpose of a study conducted by Nyang'or, Ssemugabi, and De Villiers [24] was to generate a questionnaire for evaluating offline e-learning tutorials and determine its effectiveness. The criteria used for evaluating offline e-learning tutorials was based on usability, learning theories, evaluation, and practical aspects of e-learning. These criteria were used to develop evaluation statements for the questionnaire which was applied to participants of a CD-based offline course. After making modifications based on the obtained results, their proposed instrument was grouped in four categories: (1) interface design, (2) system interaction, (3) learner-centered instructional design, and (4) system's navigation and orientation. While they consider some e-learning elements, their questionnaire was designed for offline tutorials, which have different elements than an online course. Therefore, the items used in this questionnaire are not adequate for online university courses. 
Dringus and Cohen [8], concerned about lack of support in learning management systems (LMSs), created a usability checklist for online courses to evaluate users' experience. The usability heuristic checklist is divided in the following 13 categories: (1) visibility, (2) functionality, (3) aesthetics, (4) feedback and help, (5) error prevention, (6) memorability, (7) course management, (8) interactivity, (9) flexibility, (10) consistency, (11) efficiency, (12) reducing redundancy, and (13) accessibility. This expansive list of usability heuristics can be also used in online courses. Since the focus of Dringus and Cohen's study was on LMSs, such as WebCT and Blackboard, the evaluation categories focused on the platform's usability, and some e-learning pedagogical elements are missing.

Table 1. Brief Summary of Review of Literature Findings of Criteria Used to Evaluate Usability in E-Learning

\begin{tabular}{|c|c|c|}
\hline $\begin{array}{c}\text { Evaluated } \\
\text { Usability }\end{array}$ & Criteria Suggested/Evaluated & $\begin{array}{l}\text { Studies with } \\
\text { the Criteria }\end{array}$ \\
\hline \multirow{4}{*}{ 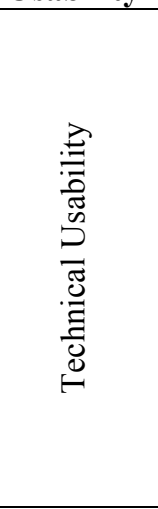 } & \multirow{4}{*}{ 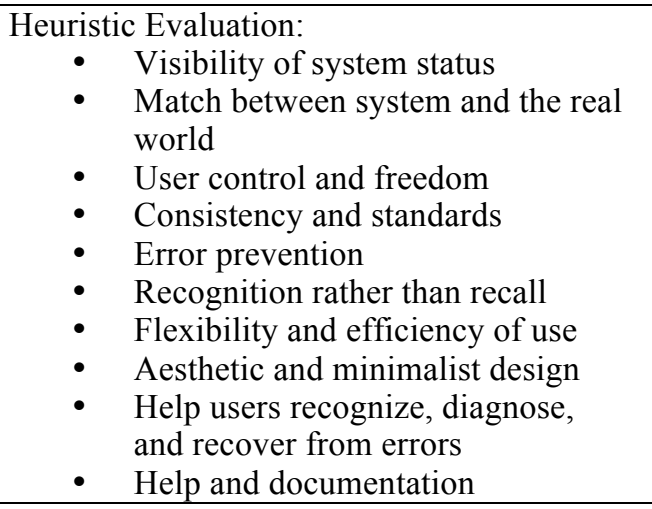 } & $\begin{array}{c}\text { Aziz, Isa, and } \\
\text { Nordin (2010) [4] }\end{array}$ \\
\hline & & $\begin{array}{c}\text { Ballard (2010) } \\
{[5]}\end{array}$ \\
\hline & & $\begin{array}{c}\text { Davids, Chikte, } \\
\text { and Halperin } \\
(2014) \\
{[7]} \\
\end{array}$ \\
\hline & & $\begin{array}{l}\text { Feldstein and Neal } \\
\text { (2006) } \\
{[9]}\end{array}$ \\
\hline \multirow{4}{*}{ 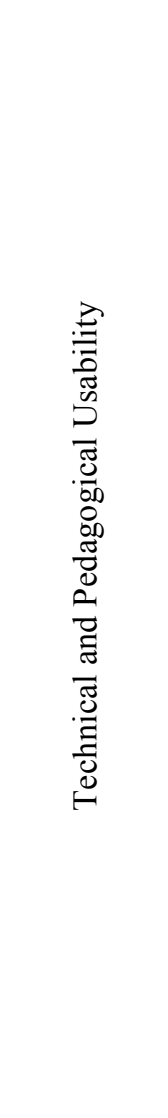 } & $\begin{array}{l}\text { - Effectiveness } \\
\text { - Saticiency } \\
\text { - } \text { Learnabion } \\
\text { Utility }\end{array}$ & $\begin{array}{c}\text { Khan, Israr, and } \\
\text { Hassan }(2010) \\
{[17]}\end{array}$ \\
\hline & $\begin{array}{ll} & \text { Interface design } \\
\text { - } & \text { System interaction } \\
\text { - } & \text { Learner-centered instructional design } \\
\end{array}$ & $\begin{array}{c}\text { Nyang'or, } \\
\text { Ssemugabi, and } \\
\text { De Villiers (2013) } \\
{[24]} \\
\end{array}$ \\
\hline & $\begin{array}{ll}\text { - } & \text { Visibility } \\
\text { - } & \text { Functionality } \\
\text { - } & \text { Feedhetics } \\
\text { - } & \text { Error prevention } \\
\text { - } & \text { Memorability } \\
\text { - } & \text { Interactivity } \\
\text { - } & \text { Flexibility } \\
\text { - } & \text { Efficiencency } \\
\text { - } & \text { Reducing redundancy } \\
\text { - } & \text { Accessibility }\end{array}$ & $\begin{array}{c}\text { Dringus and } \\
\text { Cohen (2005) } \\
{[8]}\end{array}$ \\
\hline & $\begin{array}{ll}\text { - } & \text { Content } \\
\text { - } & \text { Learning and support } \\
\text { - } & \text { Nisual design } \\
\text { - } & \text { Accesigation } \\
\text { - Interactivity } \\
\text { - } & \text { Self-Assessment and learnability }\end{array}$ & $\begin{array}{c}\text { Zaharias (2009) } \\
{[29]}\end{array}$ \\
\hline
\end{tabular}




\begin{tabular}{|l|l|l|}
\hline & $\bullet$ Motivation to learn & \\
\hline
\end{tabular}

Zaharias [29] proposed a questionnaire-based usability evaluation method for e-learning, considering cognitive and affective factors which may have an effect in e-learning usability. The eight proposed criteria in the E-learning Usability Evaluation Questionnaire are: (1) content, (2) learning and support, (3) visual design, (4) navigation, (5) accessibility, (6) interactivity, (7) self-assessment and learnability, and (8) motivation to learn. This can be considered the closest instrument to measure usability in e-learning, because many factors related to online university courses are included. However, this questionnaire is not adequate for educational settings, since it was created for corporate training settings.

Given the lack of an affordable, easily accessible instrument to measure usability in online university courses, for this study, the E-learning Usability Evaluation Questionnaire [29] will be adapted to educational settings. This will help fill the need for an instrument that allows university faculty and stakeholders a valid and reliable way to analyze and improve usability in fully online courses.

\section{METHODOLOGY}

The purpose of this study is to create an instrument to measure usability in fully online courses, based on the $E$ learning Usability Evaluation Questionnaire [29] developed originally to measure usability in corporate trainings. In order to modify the previous instrument and create a new one adapted to educational settings, the Delphi Technique will be used to collect experts' input about the items in the questionnaire. Since the purpose is to generate a new instrument, no hypothesis is stated for this study. Faculty teaching online courses and online-course designers could benefit from obtaining a usability measurement of the courses that help in examining to what degree they have incorporated usability principles and therefore improve e-learning students' experience when taking fully online courses.

This section describes the methodology that will be used to conduct the Delphi Technique and generate the modified e-learning usability questionnaire.

\section{Research Design}

A Delphi study will be used to conduct the modification process of the original E-learning Usability Evaluation Questionnaire [29] to educational settings. Delphi is a technique used to create consensus by using a series of questionnaires to collect data from selected experts. In order to be considered experts, participants should "have somewhat related backgrounds and experiences concerning the target issue, are capable of contributing helpful inputs, and are willing to revise their initial or previous judgments for the purpose of reaching or attaining consensus" [14]. The Delphi Technique was developed by Dalkey and Helmer in 1963 at the Rand Corporation in the 1950's [14]. The main areas where it has been used are education, public relations, communications, and scientific disciplines [16].

The Delphi Technique consists of a series of iterations or rounds, where the experts are given separately a first set of questions that are then returned to the researcher. The researcher collects the information and creates a summary from the results. In the following round, experts' opinion about the consensus from the previous round is gathered. The number of rounds varies depending on the experts' consensus. However, three rounds are recommended, where the last round is used to validate the final product [14]. The number of participants for this technique is variable. The researcher has to consider having an adequate number of participants. If the sample is too small, participants may not provide a representative pooling of judgments, and if the sample is too large, low response rates and many time will be required from both participants and researcher [14].

This study attempts to create a revised version of the E-learning Usability Evaluation Questionnaire developed by Zaharias [29], adapting it to educational settings. In order to create consensus from experts' opinion about the questions that should be addressed to measure usability in fully online educational courses, the use of the Delphi Technique is considered appropriate. 


\section{Participants}

A panel of experts will be invited to participate in this study. The panel will consist of university faculty experienced in teaching fully online courses and fully online course designers. Purposive sampling will be used to select participants. The criteria for participants to be invited to participate as an expert on this study include a minimum of three years of experience teaching or designing fully online courses at university level. Participants also must have willingness to participate in all the rounds needed to complete this study. Experts can be located anywhere because the expert-researcher interaction will be online.

For the first round of this study, four selected experts will be invited to participate and revise the proposed new version of the instrument. The second and following rounds of this study will require the participation of 14 experts, so ten additional experts will be invited. An email invitation to participate in all the Delphi rounds will be sent to the experts. If experts do not agree to participate in the study, more experts will be selected until the minimum number is reached.

\section{Setting}

For the purpose of the first stage of this research, the Delphi study will be conducted at The University of Texas Rio Grande Valley. Data will be collected from experts in different geographic locations using web communication tools.

\section{Instrumentation}

The E-learning Usability Evaluation Questionnaire developed by Zaharias [29] will be the base to start this study. It has a total of 49 questions divided in eight different criteria. The criteria used to measure usability in e-learning are: (1) Content, (2) Learning and Support, (3) Visual Design, (4) Navigation, (5) Accessibility, (6) Interactivity, (7) Self Assessment and Learnability, and (8) Motivation to Learn. Since the original instrument is intended for corporate settings and several questions do not apply for online courses, the original questionnaire will first be revised by the researcher in order to adapt the questions to fully online university courses. From the complete original questionnaire, some questions will be rephrased, while the rest will be kept as they are. The revised and original questions will be formatted as a questionnaire and emailed to the experts who will participate in the first round of the Delphi study.

The researcher will compile and analyze the results from Round 1, and generate a revised questionnaire to be used in Round 2. The number of rounds will be determined by experts' opinions on each round until a consensus is reached.

\section{Procedures}

Expert participants will be invited to participate in this study via email. The email will explain clearly what the purpose of the study is, and what they are required to do if they agree to participate. Once four experts agree to participate, Round 1 will be conducted and a total of 14 days will be given to respond between each round. Since the original questions are intended for e-learning in corporate settings, the purpose of Round 1 is to collect experts' opinion about the revised wording (compared to the original questions) to adapt them to fully online university courses. Following rounds will collect experts' opinion about the new questionnaire resulting from Round 1.

In order to start with Round 1, participants will be given a survey. The survey will have the 49 original items (questions) divided by criteria, as well as the revised items. Experts will compare the new items with the original ones. Some of the items remain the same. Since time is a constraint for experts, a Likert-scale will be used in order to make it easier to review all the items in the questionnaire. For each item in the questionnaire, experts will answer 5 questions. The first three questions will ask if the item is written clearly, if the item is relevant for fully online courses, and if the response of the item would be valid. To respond, experts will use a Likert-scale from 1 to 5, being 1 "Completely Disagree" and 5 "Completely Agree". The fourth question will ask if the item should be included in the questionnaire, selecting as answer "Yes" or "No". The last question for the item will be open ended. Experts will be asked to write any comments or suggest any modification for that specific item. 
Once all Round 1 participants send their responses, a new version of the usability questionnaire will be created. This new usability questionnaire will be the base to conduct Round 2. For Round 2, ten more experts will be invited to participate in the study, totaling 14 experts (4 from the first round and 10 from the second round). The survey for Round 2 will be created based on the results of Round 1, and the 14 experts will be given only the new version of the usability questionnaire to review it. It is expected a third round to validate the final questionnaire, however the number of rounds will be determined after the previous round is finished. The consequent rounds cannot be described here because of the nature of the Delphi Technique.

The validity and reliability of the new instrument generated will be a second phase of this study, with different setting, participants, and procedures.

\section{LIMITATIONS}

This study will be limited by several factors related with the generation of a new instrument based on the original usability questionnaire. For example, as stated by Hsu and Sandford [14], the Delphi technique has some limitations itself. Since it needs several stages to collect experts' opinion about a topic, there is a risk for low response rates as the stages are advancing. Also, this technique is time-consuming since it is iterative and sequential, and a potential risk of participants' withdrawal exists. The experts involved in the study may also have different experiences about online courses. Therefore, their opinions could only benefit items related to their expertise and not the overall questionnaire.

In addition, the new version of the instrument will measure usability only in one type of fully online course, with specific characteristics. This is, not all fully online courses offered are designed using the same elements; therefore, the adapted instrument may not fit to every course.

\section{SUMMARY}

Since the demand of fully online courses has increased in universities, determining their overall usability will help faculty and designers in the improvement of the courses. Studies have measured usability on e-learning environments using different instruments and considering several different criteria. The purpose of e-learning is not only that students interact with the interface but to support the acquisition of knowledge through it. In order determine usability in e-learning environments, technical and pedagogical criteria of usability should be considered.

A few instruments were found where pedagogical criteria of usability are considered. The closest instrument found to measure usability on fully online university courses is the E-learning Usability Evaluation Questionnaire developed by Zaharias [29]. Since this instrument was developed for corporate settings, the purpose of this first stage of the study is to adapt the questionnaire to educational settings by conducting a Delphi study. A second stage of this study will consider establishing the validity and reliability of the new instrument. Once the instrument is valid and reliable, for future research, the questionnaire can be applied to fully online university courses with similar characteristics in order to determine its overall usability.

\section{REFERENCES}

1. Allen, I. E., \& Seaman J. (2014). Grade change: Tracking online education in the United States. Retrieved from http://www.onlinelearningsurvey.com/reports/gradechange.pdf

2. Ardito, C., De Marisco, M., Lanziloti, R., Levialdi, S., Roselli, T., Rossano, V., \& Tersigni, M. (2004). Usability of e-learning tools. AVI '04 Proceedings of the Working Conference on Advanced Visual Interfaces, 80-84 doi: 10.1145/989863.989873

3. Armenski, G., Kostoska, M., Ristov, S., \& Gusev, M. (2014). Student satisfaction of e-learning tools for computer architecture and organization course. 2014 IEEE Global Engineering Education Conference, 630-637.

4. Aziz, M. A., Isa, W. A., \& Nordin, N. (2010) Assessing the accessibility and usability of Malaysia higher education website. 2010 International Conference on User Science Engineering (i-USEr), 203 - 208. 
5. Ballard, J. K. (2010). Web site usability: A case study of student perceptions of educational websites. (Doctoral dissertation). Retrieved from http://conservancy.umn.edu/handle/11299/91797

6. David, A., Glore, P. (2010). The impact of design and aesthetics on usability, credibility, and learning in an online environment. Online Journal of Distance Learning Administration, 13(4), 43-50. Retrieved from http://www.westga.edu/ distance/ojdla/winter134/david_glore134.html

7. Davids, M. R., Chikte, U. M., \& Halperin, M. L. (2014). Effect of improving the usability of an e-learning resource: A randomized trial. Advances in Physiology Education, 38, 155-160. doi: 10.1152/advan.00119.2013

8. Dringus, L. P., \& Cohen, M. S. (2005). An adaptable usability heuristic checklist for online courses. 35th ASEE/IEEE Frontiers in Education Conference, T2H-6 - T2H-11.

9. Feldstein, M., \& Neal, L. (2006, August). Designing usable, self-paced e-learning courses: A practical guide. Retrieved from: http://elearnmag.acm.org/featured.cfm?aid=1165344

10. Fisher, E. A., \& Wright, V. H. (2010). Improving online course design through usability testing. MERLOT Journal of Online Learning and Teaching. 6(1). 228-245.

11. Granić, A., \& Ćukušić, M. (2011). Usability testing and expert inspections complemented by educational evaluation: A case study for an e-Learning platform. Educational Technology \& Society, 14(2), 107-123.

12. Guo, Y., Zhu, Z., \& Qian, D. (2010). Supporting online learning system design with usability engineering. 2010 International Conference on Artificial Intelligence and Education (ICAIE), 718-721 doi: 10.1109/ICAIE.2010.5641511

13. Heidig, S., Müller, J., \& Reichelt, M. (2015). Emotional design in multimedia learning: Differentiation on relevant design features and their effects on emotions and learning. Computers in Human Behavior. 44, 81-95.

14. Hsu, C., \& Sandford, B. (2007). The Delphi technique: Making sense of consensus. Practical Assessment, Research \& Evaluation. 12(10).

15. $\mathrm{Hu}, \mathrm{Y}$. (2008). Motivation, usability and their interrelationships in a self-paced online learning environment (Doctoral dissertation). Retrieved from http://scholar.lib.vt.edu/theses/available/etd-09022008091550/unrestricted/Hu_Dissertation_etd.pdf

16. Kennedy, H. P. (2004). Enhancing Delphi research: Methods and results. Journal of Advanced Nursing, 45(5), 504-511.

17. Khan, M. A., Israr, N., \& Hassan, S. (2010). Usability evaluation of web office applications in collaborative writing. 2010 International Conference on Intelligent Systems, Modeling and Simulation, 146-151. doi: 10.1109/ISMS.2010.37

18. Malamed, C. (2015, April 28) Why aesthetics matter to learning. Association for Talent Development. Retrieved from: https://www.td.org/Publications/Blogs/Learning-Technologies-Blog/2015/04/Why-Aesthetics-Matter-toLearning

19. Nielsen, J. (1995a). 10 Usability heuristics for user interface design. Nielsen Norman Group. Retrieved from: http://www.nngroup.com/articles/ten-usability-heuristics/

20. Nielsen, J. (1995b). How to conduct a heuristic evaluation. Nielsen Norman Group. Retrieved from: http://www.nngroup.com/articles/how-to-conduct-a-heuristic-evaluation/

21. Nielsen, J. (2012). Usability 101: Introduction to usability. Nielsen Norman Group. Retrieved from: http://www.nngroup.com/articles/usability-101-introduction-to-usability/

22. Nokelainen, P. (2006). An empirical assessment of pedagogical usability criteria for digital learning material with elementary school students. Educational Technology \& Society, 9(2), pp 178-197.

23. Nyang'or, J. O., De Villiers, M.R. \& Ssemugabi, S. (2013). A framework for usability evaluation of an offline e-learning tutorial and its application in usability testing. In Jan Herrington et al. (Eds.), Proceedings of World Conference on Educational Multimedia, Hypermedia and Telecommunications 2013 (pp. 1097-1105). Chesapeake, VA: AACE.

24. Nyang'or, J. O., Ssemugabi, S. \& De Villiers, R.M. (2013). Optimising the effectiveness of questionnaire surveys for usability evaluation of offline e-learning tutorials. In T. Bastiaens \& G. Marks (Eds.), Proceedings of World Conference on E-Learning in Corporate, Government, Healthcare, and Higher Education 2013 (pp. 387-394). Chesapeake, VA: AACE.

25. Plantak, D., Kirinic, V. \& Klicek, B. (2010). A comparison of usability evaluation methods for e-learning systems. DAAAM International Scientific Book, 9, 271-288.

26. Plass, J., Heidig, S., Hayward, E., Homer, B., \& Um, E. (2013). Emotional design in multimedia learning: Effects of shapeand color on affect and learning. Learning and Instruction. doi: 10.1016/j.learninstruc.2013.02.006 
27. Silius, K., Tervakari, A., Pohjolainen, S. (2003). A multidisciplinary tool for the evaluation of usability, pedagogical usability, accessibility and informational quality of web-based courses. The Eleventh International PEG Conference: Powerful ICT for Teaching and Learning.

28. UsabilityNet (n.d.). What is usability? Retrieved from: http://www.usabilitynet.org/management/b_what.htm

29. Zaharias, P. (2009). Developing a usability evaluation method for e-learning applications: From functional usability to motivation to learn. International Journal of Human-Computer Interaction, 25(1), 75-98.

30. Zaharias, P., \& Koutsabasis, P. (2012). Heuristic evaluation of e-learning courses: A comparative analysis of two e-learning heuristic sets. Campus Wide Information Systems, 29(1), 45-60. doi: $10.1108 / 10650741211192046$ 